\title{
Transformation towards Human Workforce 4.0 through the Qualification Model LTA-FIT
}

\author{
Grit Rehe \\ Mittelstand 4.0- \\ Kompetenzzentrum Cottbus \\ rehe@b-tu.de
}

\author{
Robert Schneider \\ Mittelstand 4.0- \\ Kompetenzzentrum Cottbus \\ schneider@b-tu.de
}

\author{
Dr. Denny Thimm \\ Mittelstand 4.0- \\ Kompetenzzentrum Cottbus \\ thimm@b-tu.de
}

\begin{abstract}
Even though digitization is a topic of high interest and promises remarkable benefits for the German manufacturing industry, it is still in its development phase. Thus, necessities arising from it are not predictable, yet. A great obstacle that will occur is the appropriate qualification of employees at all levels, sectors and firm sizes. The integration of new technologies will have radical impact on the role and job profile of all staff members as they alter the requirements across the whole value chain and lead to new processes. Latest studies showed that an insufficient qualification of employees is one of the greatest challenges for a successful digitization. Thus, to regain a globally leading position in the manufacturing industry German companies, especially small and medium sized enterprises (SME), need to qualify their employees appropriately. The LTA-FIT model is an approach that aims to face these challenges.
\end{abstract}

\section{Introduction}

In Germany, current economic megatrends are causing an incisive transformation in production processes and their products. An aging society, rising energy prices, raw material scarcity and the demand for individualized, sustainable, smart products already challenge the manufacturing environment [1].

In addition, increasing competitive pressure from abroad exerts on the German industry. To meet the needs of today's customers, foreign companies increase their productivity by the improvement of production processes and the development of innovative goods. Thus, they are able to react instantly to the fluctuating necessities of the society. To address this challenging environment and to regain the leading market position, German companies initiated the adaption of corporate structures and production processes towards the manufacturing of customized and quick launched products.

Supporting this industrial revolution in Germany, the Ministry of Education and Research (BMBF) and the Ministry of Economic Affairs and Energy (BMWi) launched the national strategic initiative "Industrie 4.0" (Industry 4.0) in 2011 [2]. This initiative constitutes one of the key developments that shall not only face current but especially approaches future challenges. Through an increasing digitization and the interconnection of products, value chains and business models Industry 4.0 strives forward the digital manufacturing [3].

The developments associated with Industry 4.0 alter the demanded requirements across the whole value chain and partially lead to new operations. In addition, agile and data based production processes as well as business models arise, which will radically impact the role and job profile of employees and causes a need of new skills. Particularly, the demand for software developers and data analysts will tremendously increase in the next years [6].

According to a study published by a consultancy survey, German companies assume that an insufficient qualification of employees is one of the greatest challenges for a successful implementation of Industry 4.0 [6]. Thus, even in the digital age, focus must lay on the employees to ensure the competitive and innovative capacity of German companies. Early and appropriate education of junior staff and respective continuous trainings for established employees are essential for success.

Demographic aspects, current employment structures and a lack of specialized personnel in some economic sectors play an important role when designing respective qualification models. At present, companies are characterized by employees with distinct experience and competence horizons as they serve with different skills and qualification levels regarding the use of digital technologies. This trend is being reinforced by the aging society. In 1999, $44.25 \%$ 
of the employees ${ }^{1}$ were 40 years or older. Eighteen years later, this share increased to $56.21 \%$, recording an upward trend [7].

Looking at the needed improvements of digital expertise in German companies and the demographic structure, a multi-generation approach is becoming more and more important. Qualification models need a design that considers employees of all ages, the distinct levels of knowledge and especially the aim of the qualification itself.

This paper presents the qualification model LTA-FIT, which meets the needs explained above. The abbreviation LTA-FIT stands for Learning, Training, Assistance - Formats, Issues, Tools. The model mediates both, professional and methodological skills as well as personal and social skills in the context of Industry 4.0. Thereby, the recommendations published in the latest study of the social partners concerned with qualification methods and tools are regarded [8].

The paper is structured as follows. Section 2 gives an overview on the theoretical background and explains the necessity of a holistic qualification model that goes beyond the scope of learning factories. Afterwards the LTA-FIT model as possible answer to the outlined needs is introduced. In section 4 the paper describes the transfer of the model into technological applications, and thus its integration into a company's intern processes. Finally, conclusions will be given in section 5 .

\section{Theoretical framework}

\subsection{State of the art}

Traditional vocationally-oriented education in schools have long been replaced by work-based learning and competence-building [9]. According to Kock and Ellström (2011), this kind of training is seen as a key driver for the enhancement of productivity as well as for their innovation performance and competitive capacity [10].

The academic literature discusses three variants of workplace learning; formal, non-formal and informal learning. Formal learning is characterized by a high degree of planned or organized activities. This may be processed by courses or by studying relevant books and journals. Furthermore, formal learnings are attributed to certifications and/or grading [10]. Nonformal learning differs from the previous to this extent that participants are not certified or graded. Informal learning refers to acquisition of knowledge in the daily

\footnotetext{
${ }^{1}$ Here, employees with subject to social insurance contributions are meant.
}

work. This type of learning is not planned but rather occurs regularly at work, for instance, through the participation in staff-meetings, job rotation or teambased work [10].

For a successful learning design a pairing of informal and (non-)formal learning approaches shall be considered [11].

In the context of Industry 4.0, only few qualification models have been developed. Most of the studies rather follow the question of ideal learning environments and conditions to develop learning theories or to outline factors that need to be considered [9], [10], [11]. Others describe the competencies and knowledge that needs to be imparted for a successful digital qualification [12], [13], [14].

One qualification model that gained high interest in the field of digitization is the learning factory. A learning factory reflects value chain sections in an idealized mode and uses formal and informal learning approaches to serve as an optimized qualification environment [15]. In the past, such factories were built with variant areas such as manufacturing (TU Vienna [13], TU Darmstadt [16]), energy efficiency (Green Factory Bavaria [17]) or service operations processes (McKinsey Capability Center Atlanta [16]) to name but a few.

However, learning factories inhere some disadvantages. Most of them have complex designs with highly connected components, which is often associated with a tremendous amount of operational and technical challenges. Furthermore, learning factories are expensive in purchase, operation and maintenance [18]. These high costs as well as the different challenges are only manageable for financially-strong companies or institutes and may impede an implementation in SME. This assumption is supported when considering the examples of bestpractice. Abele et al. (2019) present an impressive list of 31 learning factories that they approve to be good examples [19]. An analysis of this list reveals that all of these factories are either established in large-scale enterprises such as Daimler, MAN and BMW or are located at research institutes or universities. However, since SME constitute $99.5 \%$ of all organizations in the Germany economy and $63.2 \%$ of employment, it shall be of high interest to find a learning design that is also affordable for SME [5].

Besides this, learning factories are quite inflexible when it comes to (ad-hoc) adjustments or enhancements [19]. Thus, new developments in the manufacturing sector are difficult to implement, respectively need a long lead time for realization.

In addition, learning factories do not follow a lowthreshold approach. Rather, employees are requested to train specific processes and thus, to be prepared for a 
smart production environment. Information on digitization, Industry 4.0 or future developments of the enterprise are usually not provided. Still many employees connect digitalization at work with job losses and fewer job opportunities [20]. Therefore, learning in the context of Industry 4.0 requires the sensitization and enlightenment of the employees for the topic itself and their role within the digitization process. A learning factory does not provide such scope.

Finally, learning factories depict idealized replications of workplaces [15]. Hence, they differ from the real workplaces of the individual employee. This may outface employees and hamper a successful application of acquired knowledge. An on the job accompaniment could counteract suchlike behaviors. However, current factories do not consider a downstream assistance.

Learning factories may be a good approach for the practice of specific process tasks, however, they show some weaknesses that need to be tackled.

\subsection{Research objective}

The above clarifies that learning factories are a good first move for learning in the age of digitization. However, there is still a lack of a model that sensitizes, trains and accompanies employees during the digital transition of their work(-place) and tasks to counteract negative learning processes and possibly resulting inefficient manufacturing procedures.

As mentioned before, in major the German economy constitute of SME. Thus, an appropriate qualification design must primarily meet the needs of German employees working in such companies. To ensure an implementation and application, the design has to be affordable for the companies themselves.

The LTA-FIT model refers to a qualification design that aims to cover these needs. By investigating the models' structure, core elements and workflow its suitability will be surveyed. Furthermore, the implementation of the LTA-FIT concept in a technical manner will be discussed to reveal its applicability in purely technology driven environments and to allow the concept adaption to company specific topics.

\section{Digitized qualification with LTA-FIT}

The LTA-FIT model refers to a qualification model developed by the governmental project Mittelstand 4.0Kompetenz-zentrum Cottbus (SME 4.0 Competence Center Cottbus $[4.0 \mathrm{CCC}]^{2}$ ) in cooperation with the

\footnotetext{
${ }^{2}$ www.kompetenzzentrum-cottbus.digital
}

Chair of Automation of the Brandenburg University of Technology Cottbus-Senftenberg.

Accordingly, the qualification model was developed to answer the economic requirements of a digitally qualified society in Germany.

This chapter introduces the LTA-FIT model and outlines its objective, target group, structure, core elements and workflow.

\subsection{Objective}

Within the scope of the LTA-FIT model, topics, especially those dealing with digitization in SME, are gathered and edited to communicate them subsequently by appropriate methods towards the target groups. Thereby, the models' major objective is to raise the awareness of topics related to Industry 4.0 and to increase the digital skills of the individual actors (employees, executives, owners, operation parties) as well as of the companies as a whole. Three specific targets are set, which serve as a guide for a successful increase of the digital qualification.

First, strengthening the innovation capacity in the distinct enterprises. This refers to the ability of designing and implementing in-house digitization projects in cooperation or involvement of the employees. LTA-FIT serves as basis to enable both, the management and staff members, to operate innovative, forward-looking and successful in a competitive economy.

Second, raising the awareness of, respectively strengthening already existing integrated trainings in enterprises. A continuous job-accompanying education or a hands-on mentality at the individual workplace, promises a successful and job profile oriented qualification.

Third, sensitize SME for the benefits and meanings of internal company agreements in relevant sectors such as personnel development, working hours, security, data protection or quality assurance. Such agreements create clarity for staff members and help to navigate the company through the era of digitization.

Technology enhanced qualification models based on individual and self-reflected methodologies, will improve the transformation of human workforce in the age of Industry 4.0 and thus, ensures to reach the models' objectives.

\subsection{Target group}

The LTA-FIT model primary aims to qualify SME and their staff members in Germany to safeguard a successful digital transformation in the economy. As outlined previously, SME make up the major share of 
all organizations in Germany and account for a huge portion of employment. For this reason, the models' structure gears especially towards SME, even though it is applicable in large-scale enterprises.

Within the SME, diverse target groups with different backgrounds, experiences and motivations must be defined. However, for a consistent implementation of digital technologies appropriate qualifications must address all target groups within the companies.

Firstly, executives are addressed. They are usually responsible for the implementation of new technologies. Thus, they need a detailed knowledge about the scope of application, the mode of operation and integration into existing processes.

Moreover, high attention has to be paid on the operating staff members. This target group is getting into direct contact with new implemented technologies. For this reason, it is essential that they are qualified for the usage of newly integrated machineries, software, technics and applications. Besides, the very specific and task-based qualification content, also basic knowledge must be taught to ensure an understanding for the overall context and to create acceptance for the implementation of digitization.

The introduction of new or digitized working processes requires the involvement of works councils. They need to be qualified first and foremost with regard to cross-cutting topics such as labor and data security, changes in working time models and organization as well as in new production processes. Although in Germany only a small proportion of companies have a works council, developments of process and application examples in cooperation with such councils also creates benefits for employees in companies without respective establishments. In addition, pioneer users of new technologies will probably not be found in microenterprises, but in companies with larger workforce. Therefore, it is unavoidable to include works councils.

Finally, also entrepreneurs are targeted, as they are the final decision makers in a company. Only if they understand the necessity of digitization approaches and are convinced that an implementation leads to market advantages, they will allow such innovative investments. Therefore, entrepreneurs must be sensitized for basic technologies and methods

\subsection{Structure and elements of the LTA-FIT model}

The LTA-FIT model has three core elements, the relevance-ability analysis, the qualification levels Learning, Training and Assistance as well as the didactical approach through the modules Formats,
Issues and Topics. Figure 1 depicts the models' core elements and exemplifies the coherence of the different components. In the following sections workflow and details of the core elements will be explained.

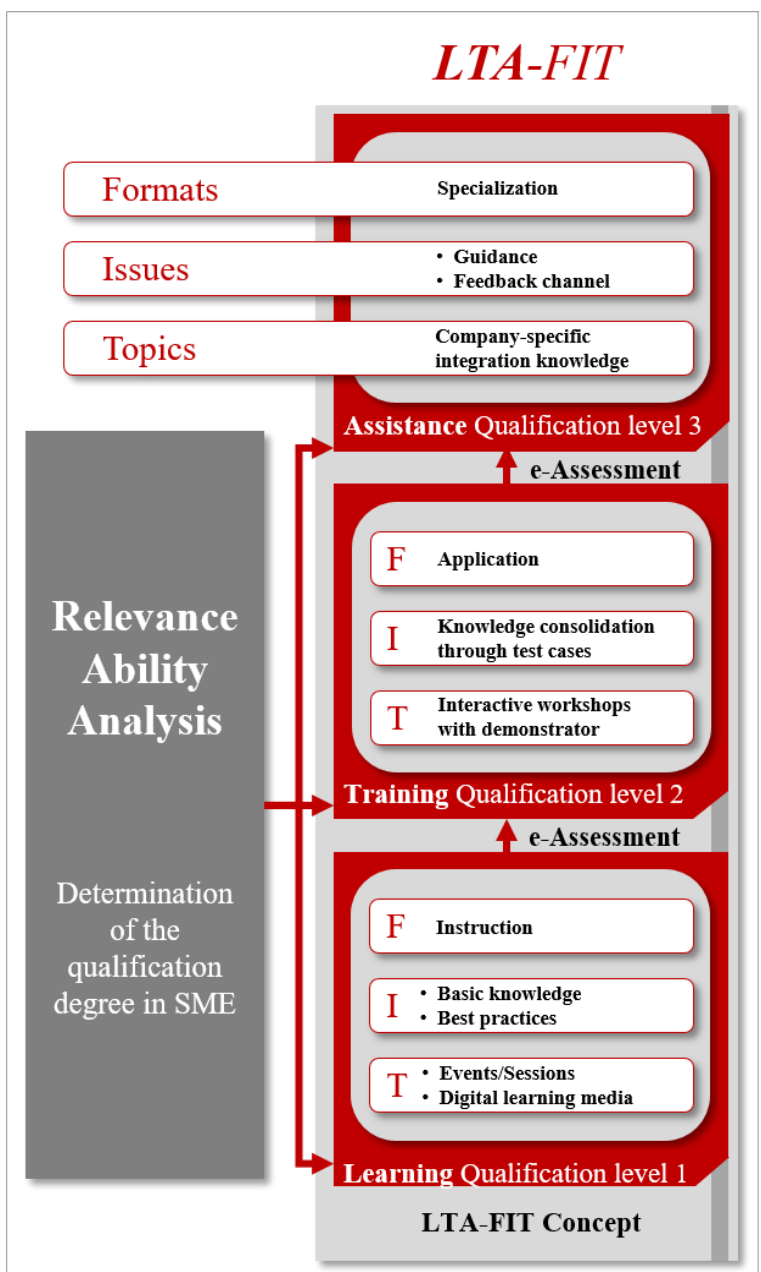

Figure 1: Structure and elements of the LTA-FIT model

3.3.1 Relevance-ability analysis The first core element embodies the developed relevance-ability analysis. This analysis constitutes the starting point of the model as it determines the degree of qualification in an enterprise and of its employees. The characteristics to determine the distinct qualification levels are based on the Fraunhofer shell model [21]. Their definitions are given in Table 1.

The analysis considers four different levels of qualification. While the lowest level (level 0) refers to the non-existence of any digitization activities and/or skills, level 3 as the highest level reflects the presence of self-organizing systems and holistic thinking among the staff members. 
Table 1: Characteristics of the different qualification levels [21]

\begin{tabular}{|c|c|c|c|}
\hline & $\begin{array}{l}\text { Degree of } \\
\text { Digitization in } \\
\text { Companies } \\
\text { (Maturity Level) }\end{array}$ & $\begin{array}{c}\text { Qualification } \\
\text { Level of Staff } \\
\text { Members } \\
\text { (Professional \& } \\
\text { Methodological } \\
\text { Skills) }\end{array}$ & $\begin{array}{c}\text { Qualification } \\
\text { Level of Staff } \\
\text { Members } \\
\text { (Individual \& } \\
\text { Social Skills) }\end{array}$ \\
\hline Q-Level 0 & Not existing & $\begin{array}{l}\text { Operational } \\
\text { process } \\
\text { knowledge, } \\
\text { ability to reflect } \\
\text { (no digitization } \\
\text { skills) }\end{array}$ & $\begin{array}{l}\text { Learning } \\
\text { receptivity, } \\
\text { willingness to } \\
\text { change, } \\
\text { communicative } \\
\text { skills }\end{array}$ \\
\hline $\begin{array}{l}\text { Q-Level } 1 \\
\text { (Learning) }\end{array}$ & $\begin{array}{l}\text { Digital data } \\
\text { analysis }\end{array}$ & $\begin{array}{l}\text { Capacity of } \\
\text { object } \\
\text { abstraction, } \\
\text { presentation skills }\end{array}$ & $\begin{array}{l}\text { Creativity, } \\
\text { problem solving } \\
\text { capabilities }\end{array}$ \\
\hline $\begin{array}{l}\text { Q-Level } 2 \\
\text { (Training) }\end{array}$ & $\begin{array}{l}\text { Interconnected } \\
\text { engineering } \\
\text { facilities, } \\
\text { processes \& } \\
\text { products }\end{array}$ & $\begin{array}{l}\text { Capacity of } \\
\text { process } \\
\text { abstraction, } \\
\text { result-driven } \\
\text { operations }\end{array}$ & $\begin{array}{l}\text { Self- } \\
\text { responsibility \& } \\
\text { ability, autonomic } \\
\text { operations, } \\
\text { willingness to } \\
\text { cooperate }\end{array}$ \\
\hline $\begin{array}{l}\text { Q-Level } \\
\text { (Assistance) }\end{array}$ & $\begin{array}{l}\text { Self-organized } \\
\text { systems }\end{array}$ & $\begin{array}{l}\text { Organizational } \\
\text { capabilities \& } \\
\text { skills }\end{array}$ & $\begin{array}{l}\text { Holistic thinking, } \\
\text { sense of } \\
\text { accountability }\end{array}$ \\
\hline
\end{tabular}

3.3.2 Qualification measures LTA-FIT and their didactics The second core element refers to the qualification level Learning, Training, Assistance LTA. They form the basis of the model as they enable companies and their employees to obtain a higher qualification. Learning measures are serving to reach the first qualification level. The Training refers to the second level and Assistance is the guidance for the last (third) level. The levels Learning and Training are completed through subsequent e-Assessments (see section 2.4.1).

Each qualification level demands an own didactical approach, as the participants of the distinct levels show different skill, experiences and knowledge. Therefore, the concept FIT (Format-Issue-Topic) is integrated into the respective qualification level.

The Format summarizes the overall objective of a measure and thus, adapts the needs of SME. The qualification content is issued by digital and analogue media and resources as well as by appropriate methods such as the application of demonstrators. The Topic describes and names the particular purpose of the qualification and provides a clear working title.

Learning - Level 1 In case the relevance-ability analysis concluded the lowest qualification level, Learning measures are suitable to impart a first basic knowledge. Through this measure rather a broad and general spread of issues is covered. The Learning measures want to raise the awareness for the importance of digitization, aim to strengthening existing individual skills and knowledge, and imparts new and basic knowledge about specific and for the participants' relevant digitization topics.

Didactically, this level makes use of instructions as Format. Typical Issues are diverse digital Learning medias, such as videos, augmented reality (AR) applications or education games which is combined with traditional lectures (blended learning). The Topics discussed refer to the demand of the participants. However, they do not overcome the imparting of basic knowledge and presentation of good practices.

Training - Level 2 Measures within the Training level aim to solidify newly won or already existing knowledge. Thus, the qualification builds upon the experiences gained through the Learning measures or know-how earnt on the job. The level is specified towards the individual needs of the participants and helps them to improve their skills through practical workshops.

This application idea refers to the Formats intended in this level. The discussed Topics refer to the demand of the participants and are oriented on their already existing knowledge. Laboratories, model factories or (mobile) demonstrators serve as Issues where participants get the opportunity to test new technologies and evaluate their relevance for the own job profile.

Assistance - Level 3 In the Assistance level the content is more specialized and addresses concrete obstacles and requirements. A strong implementation guidance and high practical relevance will be achieved through offers that are oriented to specific projects in the companies. Thus, it serves as support during the practical application, even at the own workplace. To obtain the highest possible degree of qualification in Germany, these forms of Learning opportunities are made open to other interested parties (e.g. multipliers). In this way, a professional exchange and/or a general information transfer of individual experiences is enabled.

The Topics within this qualification level are company and workplace specified. The integration during the usual working day is focused. The whole is issued by feedback channels and guiding instruments such as manuals or 3D-visualisation through $\mathrm{AR}$ application. 


\subsection{Experimental Validation through LTA-FIT applications}

3.4.1 Operating LTA-FIT in the Brandenburg industry The LTA-FIT model was developed in the German Federal state of Brandenburg by the 4.0CCC. Due to its variant rich and heterogeneous industrial composition Brandenburg served as a good and wide spread application area. Between May 2018 and May 2019 the Center offered 80 LTA-FIT workshops with more than 750 participants. The covered topics ranged from workshops transferring knowledge about new technologies to seminars that improved the participants' digital soft skills. Highly questioned topics at all qualification levels were:

- Augmented \& Virtual Reality (AR \& VR)

- Human-Robot-Collaboration

- IT Security

- Innovation Management

- Process Analytics

The particular LTA-FIT measures were offered in different settings. One setting has been the in-house offer. Following a two-week rhythm, Learning qualification seminars have been performed. In addition, qualification events where organized. During these events, participants had the opportunity to visit workshops dealing with different topics on all levels. Furthermore, on site company workshops were conducted. Here, the 4.0CCC visited SME that asked for help and qualified the staff members on site.

Moreover, the Center developed an online platform, which is continually enlarged by newly generated contents. This platform provides the qualification content of all offline workshops as well as additional Learning material. This LTA-FIT platform allows a time and location independent qualification for interested parties. In addition to the qualification contents, also e-Assessments for the levels Learning and Training are available on this platform. The assessments allow participants to review their newly gained knowledge and to examine, whether further qualifications for a particular level are required.

3.4.2 Gained experiences The gradual approach of the LTA-FIT model shows high acceptance. Both, quantitative and qualitative evaluations depict a high satisfaction of the participants. Figure 2 gives detailed information on this.

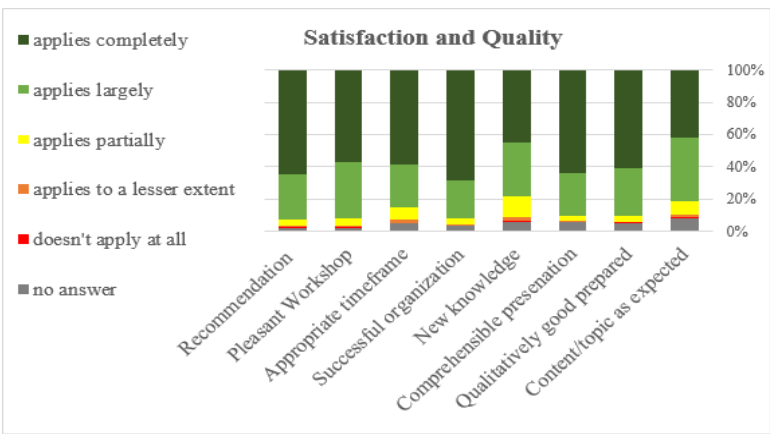

Figure 2: Evaluation results

In addition, it became clear that operation practices as approach under the level Assistance, are demanded as much as basic learnings. Work-based learning and Learning-by-doing are important methods and are common applied qualification approach in SME. Thus, also in the era of digitization. This perception is already supported by the study "Arbeit 4.0" (Work 4.0) [22].

\section{Reaching LTA-FIT operational maturity}

The experiences of the LTA-FIT model in the previous described form of application, encouraged the 4.0CCC to go one step ahead. Thus, the model has been transferred and matured into two different technical solutions, that are applicable for the integration into a company's intern processes. This strategy allows companies to adopt individual topics and makes LTAFIT portable.

\subsection{LTA-FIT implemented in AR-glasses}

AR offers completely new opportunities. This technology transfers virtual pictures into reality and thus, provides additional information.

The 4.0CCC adopted these conditions and developed an LTA-FIT application for AR-glasses (here HoloLens ${ }^{\circledR} \mathrm{I}$ ). The application aims to support the qualification in the fields of assembling, (remote) maintenance, production and much more. Representing these various possible applications, the Center established a demonstrator showing the LTA-FIT qualification of an assembly process.

Just like the basic LTA-FIT model, the technological approach offers the modules Learning, Training and Assistance (see Figure 3). 


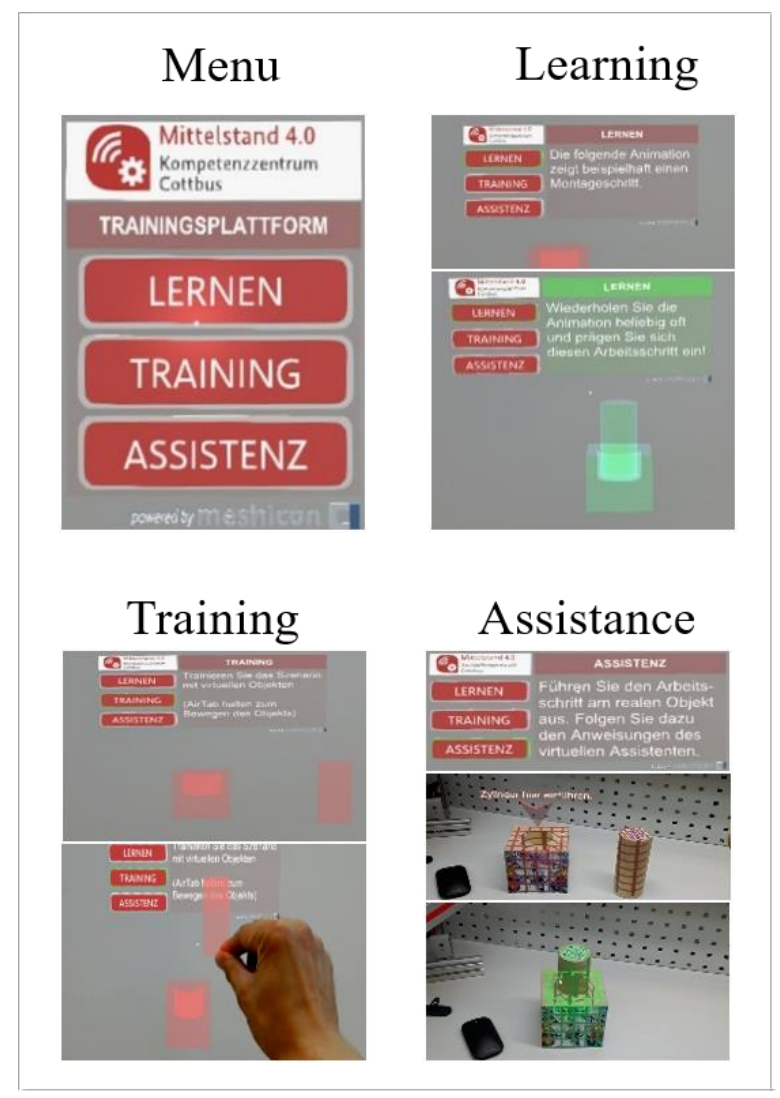

Figure 3: LTA-FIT application for AR-glasses exemplifying an assembling process

Within the Learning module the user is taught how to assemble a cylinder with a cube. For this purpose, the assembling process itself combined with a short instruction is displayed virtually. Simultaneously, the colors red, for an incomplete or wrong assembly, and green, standing for a successful assembly, are introduced.

In the subsequent Training module, users can apply their newly won knowledge. Under a short instruction, the user needs to assemble a virtual cylinder and cube as taught during the Learning phase. The Training aims to consolidate the knowledge, to the point that the user is able to carry out the whole assembly independently. In case of success cylinder and cube lights up in a green color.

During the final module - Assistance - users must assemble a real cylinder with a cube. The LTA-FIT application recognizes and tracks the real cylinder and cube, and thus, is able to detect, whether the assembly have been carried out successfully or not. This enables a real-time Assistance, especially for new and sophisticated assembly processes. Concurrently, a quality management through Assistance is provided.

Each module of the LTA-FIT AR application can be started individually and repeated as often as desired.
Through this approach an individual qualification based on the users' individual capabilities can be assured. Moreover, no additional accompaniment by a proficient is necessary.

This modular LTA-FIT application is adoptable to any manufacturing company and provides a new, individual, independent and futuristic qualification method.

\subsection{LTA-FIT as tablet-application}

In the manufacturing sector, occupational safety is a topic of high concern. Depending on the industry, protective suits are an important element of the staff security. Especially, within the steel production many different protective suits with different properties respective their operating site are used. In order to assure an appropriate use of the suits in the correct environment, comprehensive trainings are required.

For these trainings, the 4.0CCC designed an Android-based tablet application. Similar to the ARglass application a menu offers the three modules Learning, Training, Assistance from which the user can choose. Figure 4 displays this menu, together with the three modules.

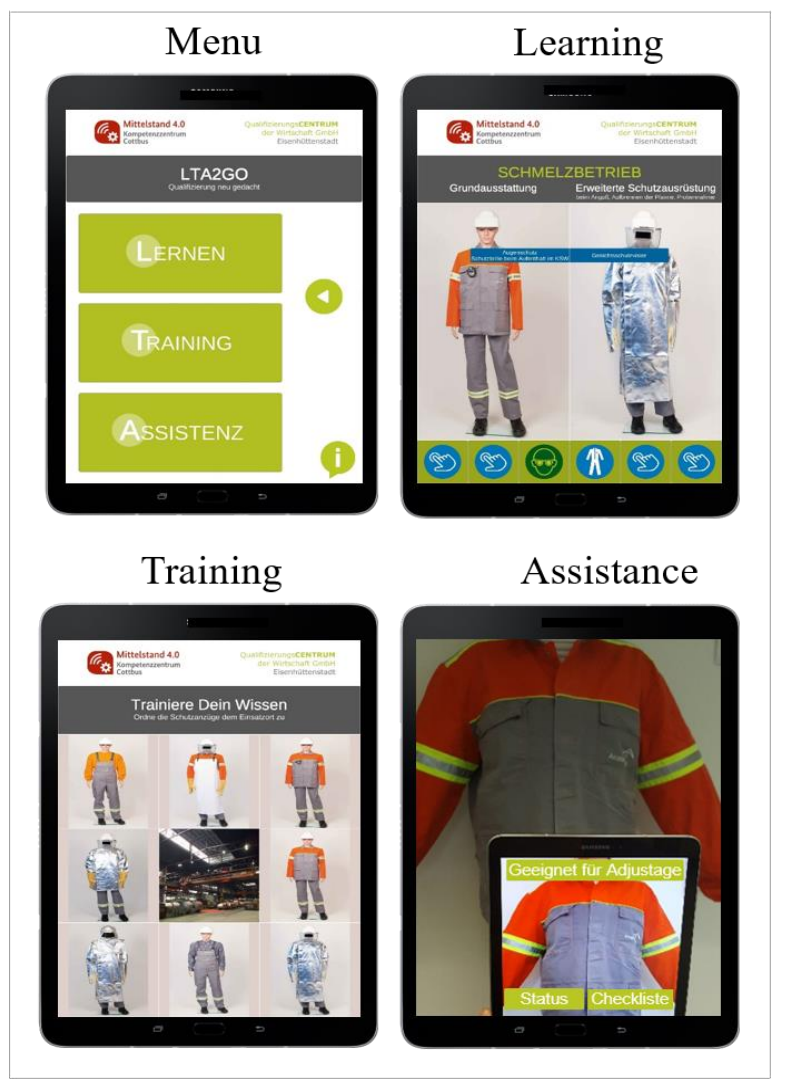

Figure 4: Qualification of protective suit properties and application. 
In the Learning section, information about the particular suits, their individual properties, their components and application areas are provided. For an interactive Learning, both symbols and pictures are equipped with features to serve as a tool with additional information.

A hands-on and ludic mentality is also included during the Training. Based on the gained knowledge users have to match the protective suits with their respect operation site. A level system shows the Training progress encouraging the individual user to deepen the knowledge.

The Assistance module is designed for an on the job application. Based on AR the different suits can be scanned and extra information regarding their properties and operation site occur on the tablet (see Figure 4 -Assistance). In this way, employees are supported on their job, as the application helps to clarify uncertainties and supports the occupational safety.

Similar to the development presented under chapter 4.1, the tablet-based application offers an individual, time and location independent, repeatable and mobile qualification. Also, the topics that shall be imparted can be customized in accordance to the companies' necessities.

\section{Conclusions and Outlook}

Digitization and its implementation in the German industry is already in process with the aim to regain the global leadership in the manufacturing industry. Especially, SME are highly concerned with this topic. As the greatest share of German organizations, they need to adapt new arising technologies to keep up with international markets. Besides the adaption of such technologies, also an appropriate qualification is required. All, entrepreneurs, executives, operating staff and works councils need to understand the necessity of Industry 4.0 with their associated changes.

For the transfer of the respective knowledge and the qualification of the affected staff members, the SME 4.0 Competence Center Cottbus developed the LTAFIT model. The modules Learning, Training and Assistance build upon each other and allow a stepwise qualification in accordance to the individual level.

The Learning level catches up with those employees that are highly concerned with current and future developments on Industry 4.0, worried about possible negative impacts on own job profiles and uncertain whether they are able to meet future requirements. Within the Training phase individual skills are trained by using certain knowledge and thus, to be prepared for a digitized workplace. Through the
Assistance employees get support on the job to address uncertainties and specific workplace demands.

Both, Learning and Training follow a rather formal learning concept. However, the Assistance pillar uses an informal learning design and thus, ensures a (non-) formal and informal approach as recommended by previous researches. This permits the mediation of variant competences as demanded by diverse researchers.

Comparing the model with learning factories it become apparent that such factories may serve as a part of the Training pillar. The similarities of Training and the learning factory concepts arise from the utilized Issues of the model. An integration of learning factories in the LTA-FIT model may be an interesting strategy that shall be considered for further developments.

The transfer of the LTA-FIT model into technical solutions enable an individual, time and location independent, repeatable and mobile qualification of each single employee. Furthermore, they allow an adaptation to a broad field of industries and topics and may serve as a blueprint. In addition, the technical implementation allows an adoption of the model to every learning environment or condition and thus can make use of previous research.

The model is especially of interest in SME. SME have in comparison to large-sized companies a weak manning level. Therefore, individual employees need to cover different workspaces. Often they are tasked solely, so that an overlapping with the responsibilities of others is rarely given. These circumstances demand an individual oriented qualification. Moreover, the costs for such individual trainings need to be kept on a low level, as they are probably performed with the majority of staff members.

The LTA-FIT is adjusted to such situations, as a topic specific and knowledge oriented learning at the workplace is supported. The technical solutions serve as inexpensive templates for the adoption of individual topics and thus, are affordable for SME.

In conclusion, the model complements existing education and training concepts and helps to bring out, secure and retain skilled workers in German SME.

The Chair of Automation was awarded as European Digital Innovation Hub in 2019 [23]. This in turn will support a roll-out of the LTA-FIT model into a wider European SEM audience.

\section{Acknowledgment}

This publication is funded and supported by the German Federal Ministry of Economic Affairs and Energy through the initiative Mittelstand-Digital. 
Mittelstand-Digital informs small and medium-sized enterprises about the opportunities and challenges of digitization. 26 regional centers of excellence help the small retailer as well as the larger production site with expert knowledge, demonstration centers, networks for the exchange of experience and practical examples. One of these regional centers is the SME 4.0 Competence Center Cottbus (Mittelstand 4.0Kompetenzzentrum Cottbus) with the project number 01MF17001A

tu.de/en/automation/research/projects/ current-projects\#c174887).

\section{References}

[1] E. Westkämper, "Struktureller Wandel durch Megatrends”, „Digitale Produktion“, Springer Vieweg Berlin, 2013, pp. 7-8.

[2] K. Kagermann, W. Wahlster, J. Helbig, „Recommendations for Implementing the Strategic Initiative INDUSTRIE 4.0. Securing the Future of German Manufacturing Industry - Final Report of the Industry 4.0 Working Group", National Academy of Science and Engineering, Berlin, 2013.

[3] European Commission, "Digital Transformation Monitor - Germany: Industrie 4.0", 2017 [Online] Available: https://ec.europa.eu/growth/toolsdatabases/dem/monitor/sites/default/files/DTM_Industrie \%204.0.pdf, last access: Jun. 06 ${ }^{\text {th }}, 2019$.

[4] R. Drath, A. Horch, "Industrie 4.0 - Hit or Hype? [industry forum]", IEEE Industrial Electronics Magazine, vol. 8, no. 2, 2014, pp. 56-58.

[5] European Commission, "2016 SBA Fact Sheet Germany", 2016 [Online] Available: http://ec.europa.eu/growth/smes/business-friendlyenvironment/performance-review en, last access: Jun. 06 $6^{\text {th }}, 2019$

[6] R. Geissbauer, S. Schrauf, V. Koch, S. Kuge, „Industry 4.0 - Opportunities and Challenges oft he Industrial Internet", PricewaterhouseCoopers Aktiengesellschaft Wirtschaftsprüfungsgesellschaft, Frankfurt am Main, 2014.

[7] Bundesagentur für Arbeit, „Beschäftigte nach Altersgruppen - Deutschland, West/Ost und Länger (Zeitreihe Quartalszahlen)“, 2019 [Online] Available: https://statistik.arbeitsagentur.de/Navigation/Statistik/Stat istik-nach-Themen/Beschaeftigung/Beschaeftigte/ Beschaeftigte-Nav.html, last access: Jun. 07 ${ }^{\text {th }}, 2019$

[8] Gesamtmetall, VDMA, ZVEI, IG Metall, "Agiles Verfahren- Ausbildung und Qualifizierung für Industrie 4.0. Handlungsempfehlungen der Sozialpartner", 2017 [Online] Available: https://www.gesamtmetall.de/sites/ default/files/downloads/basispapier agiles verfahren ver sand_17-03-28.pdf, last access: Jun. 07 ${ }^{\text {th }}, 2019$

[9] K. Illeris, "Workplace learning and learning theory" Journal of Workplace Learning, vol. 15, no 4, 2003, pp. $167-178$

[10] H. Kock, P.-E. Ellström "Formal and integrated strategies for competence development in SMEs," Journal of European Industrial Training, vol. 35, no. 1, 2011, pp. $71-88$

[11] P. Tynjälä "Perspectives into learning at the workplace," Educational Research Review 3, 2008, pp. 130-154, http://s3.amazonaws.com/assets.paboweb.nl/assets/353/ Werkplekleren_Educational_Research_Review.pdf

[12] A. Schmidt, C. Kunzmann "Towards a Human Resource Development Ontology for Combining Competence Management and Technology-Enhanced Workplace Learning," in On the Move to Meaningful Internet Systems, vol. 4278, Springer, Berlin, Heidelberg, 2006

[13] S.Erol, A. Jäger, P. Hold, K. Ott, W. Sihn „Tangible Industry 4.0: a scenario-based approach to learning for the future of production," Procedia CIRP, vol. 54, 2016, pp. 13-18

[14] S. Adolph, M. Tisch, J. Metternich „Challenges and approaches to competency development for future production," Journal of International Scientific Publications, vol. 12, 2014, pp. 1001-1010

[15] M. Tisch, C. Hertle, E. Abele, J. Metternich \& R. Tenberg „Learning factory design: a competencyoriented approach integrating three design levels," International Journal of Computer Integrated Manufacturing, vol. 29, no. 12, 2016, pp. 1355-1375

[16] E. Abele, J. Metternich, M. Tisch, G. Chryssolouris, W. Sihn, H. ElMaraghy, V. Hummel, and F. Ranz, "Learning Factories for research, education, and training," Procedia CIRP, vol. 32, 2015, pp. 1-6

[17] S. Kreitlein, A. Höft, S. Schwender, and J. Franke, "Green Factories Bavaria: A Network of Distributed Learning Factories for Energy Efficient Production," Procedia CIRP, vol. 32, 2015, pp. 58-63

[18] R. Scheid "Learning Factories in Vocational Schools," in Digital Workplace Learning - Bridging Formal and Informal Learning with Digital Technologies, Springer, Mannheim, 2018, pp. 271-287

[19] E. Abele, J. Metternicht, M. Tisch „Learning Factories: Concepts, Guidlines, Best-practice examples,“ Springer, Zürich, 2019

[20] C. Adam, C. Aringer-Walch , K. Bengler, "Digitalization in Manufacturing - Employees, Do You Want to Work There?," in Proceedings of the 20th 
Congress of the International Ergonomics Association 2018, vol 825, Springer Cham, 2019, pp. 267-275

[21] Fraunhofer Academy, "Fraunhofer-Schalenmodell Industrie 4.0“, 2017 [Online] Available: https://www.academy.fraunhofer.de/de/corporateLearning/industrie40/fraunhofer-schalenmodellindustrie-4-0.html, last access: Jun. $08^{\text {th }}, 2019$

[22] C. Kampe, A. Walter, D. Porep, „Langfassung der Studie Arbeit 4.0 in Brandenburg - Ergebnisse zu
Digitalisierungsniveaus, Beschäftigungseffekten, Arbeitsformen, Qualifizierungsbedarfen", Wirtschaftsförderung Land Brandenburg $\mathrm{GmbH}$, Potsdam, 2018.

[23] European Commission, „Digital Innovation Hubs“, 2019 [Online] Available: http://s3platform.jrc.ec.europa.eu/digital-innovationhubs-tool/-/dih/1019/view, last access: Jun. 13 ${ }^{\text {th }}, 2019$ 